\title{
Preoperative saccharine experience and postoperative fluid preference in adrenalectomized rats'
}

\author{
DOUGLAS L. GRIMSLEY ${ }^{2}$ AND LESUIE E. FISHER, Jr. \\ FLORIDA STATE UNIVERSITY
}

Drinking behaviors of adrenalectomized and sham-operated rats were compared under preoperative conditions of saccharine and salt solutions, or only distilled water, available. Saccharine experience did not contribute to a significant change in postoperative drinking behavior; adrenalectomized $S$, regardless of experience, drank less saccharine solution than sham Ss, and all groups consumed similar amounts of $\mathrm{NaCl}$. These results contradict other studies in which a sugar solution was the "irrelevant" experience fluid.

The loss of sodium via the urine in adrenalectomized rats is associated with increased salt appetite which is usually sufficient to keep the animal free from the symptoms of salt deficiency. Richter (1947) concluded that when a particular dietary item is missing, the rat promptly demonstrates a "specific hunger" for that substance. Others have argued that compensatory appetitive choices do not necessarily occur immediately following the development of a nutritional need (Scott \& Verney, 1947). Harriman (1955) reinforced these conclusions by showing that rats given the opportuntty to establish a strong preoperative preference for sugar over salt maintained the sugar preference subsequent to adrenalectomy and failed to manifest the usual increase in salt consumption. Even in the presence of an $\mathrm{NaCl}$ solution, several adrenalectomized rats died and survivors displayed marked weight losses. Since these results contradict most of the popular thinking about salt seeking in the adrenalectomized rat and, Indeed, question the validity of the specific hunger hypothesis, further investigation seemed warranted.

The purpose of the present study was to test the prediction that animals given the opportumity to establish a preference for a nonnutrient sweet solution. such as saccharine, would maintain this preference subsequent to adrenalectomy. Saccharine was chosen so that hypoglycemia (one of the effects of adrenalectomy) would not be reflected in the choice of solution. Subleets and Apparafus

The 24 male albino rats of the Dublin strain (Dublin, Va.) were 120 days old at the start of experimentation.

All Ss were maintained ad lib on a $\mathrm{Na}$ deficient diet (Hartroft formula, General Biochemicals) which contained $4.3 \mathrm{mg}$ of $\mathrm{Na}$ per $100 \mathrm{~g}$. The standard food cup at the rear of each cage was filled daily.

The experimental animals received saccharine and salt solutions preoperatively while the controls received only distilled water. Concentrations of $0.9 \%$ $\mathrm{NaCl}$ and $0.1 \%$ calcium saccharine were mixed on a weight/volume basis with distilled water as the solvent. These solutions were presented in two calibrated 100 $\mathrm{ml}$ bottles mounted on the cage front approximately 4 in. apart. To control for position effect and possible preference for a particular drinking tube, the method of Bare (1949) was used-each solution was presented in each position in each bottle.

Precedare

The 24 Ss were randomly divided between two conditions. Food and liquids were freely available and intake was recorded daily. Body weights were determined every third day.

Condition 1. Groups $A$ and $B(N=7$ and 5, respectively) received both saccharine and $\mathrm{NaCl}$ during the 15 preoperative days (Experience groups). On Day 16, the animals of Group $A$ were bilaterally adrenalectomized and those of Group B were bilaterally sham adrenalectomized. Following the operation, both groups continued to receive the $\mathrm{NaCl}$ and saccharine for the 20 postoperative days.

Condition 2 Groups $\mathrm{C}$ and $\mathrm{D}(\mathrm{N}=7$ and 5, respectively) received only distllled water during the preoperative period (No Experience groups). On Day 16 the animals of Group $C$ were bilaterally adrenalectomized and those of Group D were sham operated. Postoperatively, these Ss were given access to the $\mathrm{NaCl}$ and saccharine soluttons.

Postmortem veriflcation of adrenalectomy was gained at the end of the experiment.

Resule

Mean saccharine intake for the final preoperative and the 20 postoperative days is plotted in Fig. 1. Both Experienced groups established a strong pref-

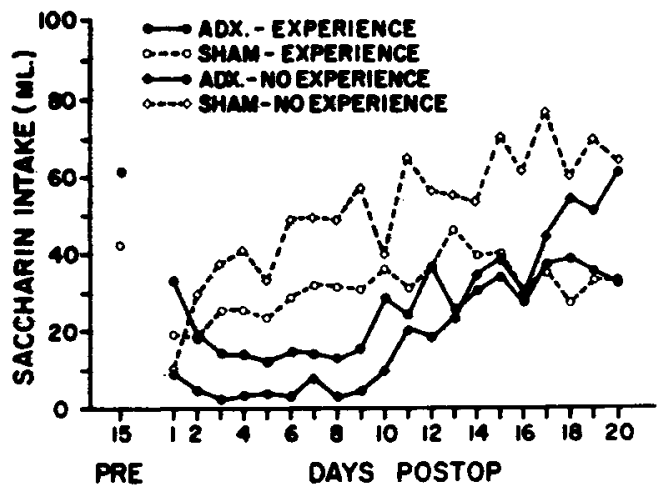

Fi2. 1. Mean mechurime idule for the final preop and the 20 postop days. 


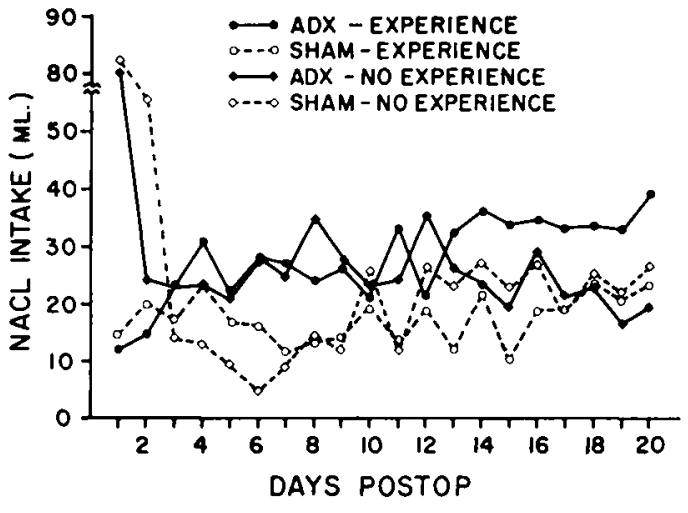

Fig. 2. Mean $\mathrm{NaCl}$ intake for the 20 postop days.

erence during the 15 preoperative days. Postoperatively, the adrenalectomized animals drank less saccharine compared to the sham operated animals. The adrenalectomized Experience animals dramatically decreased saccharine consumption and displayed a pattern of intake similar to that of the No Experience adrenalectomy group. Analysis of variance of the postoperative saccharine intake data indicated a significant difference between groups $(F=3.23$, df $=3 / 19$, $\mathrm{p}<.05)$. Further analysis by the Newman-Keuls procedure indicated (a) no difference between adrenalectomized groups, and (b) that the No Experience sham adrenalectomized group consumed significantly more than the other three groups for Days 3 through 11. By Day 12 the groups no longer showed any significant difference in saccharine intake.

Figure 2 shows the mean $\mathrm{NaCl}$ intake for the 20 postoperative days. With the exception of the first two days, differences in $\mathrm{NaCl}$ intake were not statistically significant $(F<1)$. A relatively large consumption by the No Experience groups on Days 1 and 2 can probably be attributed to the absence of $\mathrm{NaCl}$ during the preoperative period.

Analysis of weight showed a significant increase over trials $(F=14.69, \mathrm{df}=5 / 95, \mathrm{p}<.01)$, but there were no significant differences between groups. Food intake was depressed in the adrenalectomized groups for about five days postoperatively. By Day 7 there were no group differences in food intake.

\section{Discussion}

The problem posed in this experiment was to investigate whether the development of a preoperative preference for saccharine over salt would prevent the occurrence of the typical postoperative increase in salt intake. The data show that this was not the case. Both Experience and No Experience adrenalectomized animals consumed approximately the same quantity of saccharine and $\mathrm{NaCl}$. With the exception of Days 1 and 2 postoperative $\mathrm{NaCl}$ intake was similar for all groups. Since all Ss survived the experiment, showed normal postoperative growth and weight gain, and no symptoms associated with sodium deficiency, it appears that $\mathrm{NaCl}$ intake for all groups was sufficient to maintain a normal electrolyte balance.

These results are not consistent with what would be expected based on the findings of Harriman (1955), who reported that the typical postoperative increase in salt intake by adrenalectomized rats is prevented by a preoperatively established irrelevant sugar preference. This difference in results may be due in part to Harriman's use of sugar as an "irrelevant" fluid preference. It is well established that hypoglycemia follows adrenalectomy (e.g., Long, Katzin, \& Fry, 1940). Harriman's experienced animals, those which had the opportunity to establish a preoperative sugar preference which was maintained subsequent to adrenalectomy, may have been satisfying a specific bodily need (i.e., regulation of blood sugar level) although generally, regulation of electrolyte balance is considered to be of overriding importance. In the present experiment Ss would not be expected to show such a preference for saccharin following adrenalectomy because of the lack of postingestional cues provided by saccharine.

The fact that significant amounts of both saccharine and $\mathrm{NaCl}$ were consumed postoperatively by all groups while showing similar growth rates suggests that two factors were regulating fluid intake: (1) a specific bodily need for sodium chloride, and (2) a taste preference for saccharine.

\section{References}

BARE, J. K. The specific hunger for sodium chloride in normal and adrenalectomized rats. J. comp. physiol. Psychol, 1949, 42, 242-253.

HARRIMAN, A. E. The effect of a preoperative preference for sugar over salt upon compensatory salt selection by adrenalectomized rats. J. Nutrition, 1955, 57, 271.276.

LONG, C. N., KATZIN, B., \& FRY, E. G. The adrenal cortex and carbohydrate metabolism. Endocrinology, 1940, 26, 309-344.

RICHTER, C. P. Biology of drives. J. comp. physiol Psychol, 1947, 40, 129-134.

SCOTT, E. M., \& VERNEY, E. L. Self selection of diet. IV. The nature of appetites for B vitamins. J. Nutrition, 1947, 34, 471-480.

\section{Notes}

1. This research was supported in part by the Research Participation Program for College Teachers of the National Science Foundation and by grants MHII281-01 and MH11906-01 from the National Institute of Mental Health.

2. Now at the Human Resources Research Office, Presidio of Monterey, California. 